\title{
Children as Participants of Clinical Research
}

Nüket Büken ${ }^{1}$

\section{Klinik Araştırmaların Katıımcısı Olarak Çocuklar}

'Department of Medical History and Ethics, Hacettepe University School of Medicine, Ankara, Turkey

\begin{abstract}
This study presents an overview of the scientific and ethical issues pertaining to the most controversial areas of experimentation on humans (research with children subjects, risk/benefit estimation in paediatric research maturity of children to consent to medical research). Over the past decade, the questions regarding research ethics related to this issue have continuously evolved. The major objective of this paper is that each of these issues will continue to pose new ethical questions and mechanisms in relevant areas for ongoing considerations of these questions. It is essential that we are aware of the ethical issues in various paediatric research studies an continue to search for answers for the numerous ethical challenges, being aware of the vulnerability/defenselessness and capacity development of child participants.
\end{abstract}

Keywords: Children, clinical research, human subjects, paediatric research ethics

\section{Introduction}

In terms of ethics, the answer to the question "Why is clinical research necessary?" is the same as the answer to the question "Why is clinical practice necessary?" In other words, clinical research ethics almost entirely depends on clinical practice ethics. Medical practice focuses on the patient as an individual, and each clinical decision includes many options. Therefore, the physician tries to learn other options during medical practice although current methods are useful. In that sense, clinical research can be considered a regular part of clinical practice. On the other hand, ethical problems are more likely to occur if the treatment is based on untested theories or is
Özet

Bu makale çocuklar üzerinde yapılan klinik araştırmalarda, bilimsel ve etik açıdan en tartışmalı konularda, genel bir bakış sunar (çocuklar üzerinde yürütülen araştırmalar, bu araştırmalarda risk/yarar tahmini, çocukların tıbbi araştırmaya rıza verme olgunluğu). Geçtiğimiz on yıl içinde bu konuda araştırma etiği ile ilgili sorular sürekli olarak gelişmiş̧ir. Bu yazının başlıca amacı, bu konuların her birinin yeni sorunlar ve oluşacak yeni düşünceler için ilgili alanda yeni etik sorular ve mekanizmalar oluşturmaya devam edecek olduğunun gösterilmesidir. Esas olan, pediatri alanına özgü olan çeşitli araştırma etiği konularının farkında olmak, çocuk katılımcıların örselenebilirliğinin/savunmasızlığının ve kapasite geliştirebilmelerinin farkında olarak, pek çok etik soruna cevap aramaya devam etmektir.

Anahtar Kelimeler: Çocuklar, klinik araştırma, araştırma gönüllüleri, pediatrik araştırmalarda etik

impractical since the referenced theories do not have sufficient clarity and detail. Therefore, the requirement to test the diagnosis and treatment scientifically is a moral condition.

Children are physiologically, psychologically, and developmentally different from adults. Interventions performed on children can produce specific results. Therefore, it is important to perform development and age-related research considering their best interests. All medical products for children must be evaluated scientifically before being introduced into the market. Differences in pharmacokinetic and pharmacodynamic parameters and adverse reactions are more common in children.
Correspondence Address / Yazışma Adresi

Nüket Büken

Hacettepe Üniversitesi Tıp Fakültesi, Tıp Tarihi ve Etik Anabilim Dalı, Ankara-Türkiye

E-mail: buken@hacettepe.edu.tr OCopyright 2017 by Pediatric
Infectious Diseases Society -Available online at www.cocukenfeksiyon.org ○Telif Hakkı 2017 Çocuk Enfeksiyon Hastalıkları Derneği -Makale metnine www.cocukenfeksiyon.org web sayfasından ulaşılabilir 


\section{Necessity of Paediatric Research}

Research involving children also have goals based on child-specific qualifications. Here, the main goal is to increase knowledge with regard to children and primarily includes the followings.

- Protecting children from damage

- Providing benefits to children as individuals

- $\quad$ Providing benefits to children as a group

In addition to the above-mentioned goals, research is being carried out in order not to discriminate against children and to ensure equity. In studies including children, impartiality means respect for the need for their protection from excessive and unnecessary damage, and objective voluntary selection in accordance with the method. Maintaining this kind of research as a matter of fairness means not unnecessarily depriving children from protection as a group, and providing benefits from their participation in the research activity. Not accepting their participation in the research simply due to being children would be unfair when compared to adults. Additionally, the researches on children are being carried out with the expectation of providing benefit for the community as a whole as well as to improve children's health, to prevent diseases, and to evaluate their care.

On the other hand, there are different opinions as to whether children should be participants in non-therapeutic research, while the participation of children in therapeutic research is considered an opportunity for them. According to some views, it is appropriate for children to participate in research due to the fact that they have the obligation as they are members of moral society. Those, who object to this view, suggest that children are vulnerable/defenseless and therefore, they cannot be subjected to the same responsibilities and tasks as adults.

A healthy child should not be considered as a healthy volunteer since he or she is not able to give consent and he or she is defenseless. It is essential that the studies, which can be performed on adults, should not be performed on children. Healthy children can be included only in the presence of exceptions to this. In some special cases, it may be necessary to conduct research on healthy children. Prophylactic studies or paediatric vaccination studies may be given as examples. Older children are recommended to be included in the research instead of small children, if possible.

At this point, the question "Can research on growth and development, which cannot be carried out on adults, prevent children's diseases?" seems to be plausible. The thesis that adults should be used as research volunteers rather than risking children at various stages of growth and development can is controversial. Although the use of adults and animals or in vitro studies is sufficient in obtaining some information about humans, in certain cases, only research involving children can provide useful information about the field in question. In conclusion, research involving adults are not able to completely meet all the requirements for information on children's health and care. Relying on research involving adults as an informational base for children's health and care can be dangerous in their care. Therefore, it is inevitable for children to participate in research on paediatrics.

As a general rule, clinical trials (particularly, clinical pharmacokinetic studies) frequently performed on healthy adults are not conducted on healthy children. Paediatric studies mostly involve sick children who are being treated for a specific medical indication which is not directly related to the research being conducted. Therefore, the approved approach in paediatric practices and research involves requesting the consent of the parents or guardian to include sick children in the research, showing special sensitivity to the problems of sick-volunteer children and their parents with regard to the research or treatment, supporting the participation of sick children in research by fully complying with national and international regulations on medical research.

Responsibility of the Researcher in Paediatric Research

On the other hand, any research that is to be conducted on infants or children who are hospitalised for the treatment, leads the patients and parents to get worried. There are concerns with regard to these procedures which are compulsory in terms of research, which may change the planned direction of the treatment or extend the length of stay in the hospital. Due to the involvement of volunteering patients in clinical trials, it is highly important that the researcher understands and respects the requests and expectations for changing the planned form of the medical treatment or not being influenced adversely. Firstly, the researcher should obtain information about the status of the patient, examine the medical records carefully, and must discuss the subject with the primary care physician before informing the patient or parents of the research. After the potential patient-volunteer has been identified, the support of the primary physician of the patient should be provided, the study protocol should be explained to the patient and parents, and study procedures and results of experimental findings should be carefully and completely examined. The researcher should show to the patient and parents that the working procedures to be applied will not cause any change in the planned course of the medical treatment, that preventive measures would be taken, and that all risks accompanied with the participation of the child will be minimized. In addition, patients and parents should be clearly informed that they have the capacity to give the final decision for participation in the research. Lastly and most impor- 
tantly, the researcher needs to discuss with the patient and parents the concerns that accompany the health, safety and well-being of the patient and that are prioritized for him/her. Although such an approach requires a significant amount of time and resources for the researcher, it is stated that it would be beneficial in terms of successfully conducting and finalizing the research, and fulfilling the responsibilities. In other words, success in involving children in research is directly linked with the relationship between the researcher and patient and his/ her parents.

In order for sick children to participate in research in terms of ethics, firstly, the following conditions must be met:

- Assessing the patient motivation related to the starting the study, and being specifically sensitive to the needs of patients and parents.

- $\quad$ Raising the level of patient benefit through the provision of financial resources to meet the basic needs of the patient or the parents (transportation, meals, child care for the siblings of the patient, etc.).

- Providing information to the primary care physician regarding the patient's status and/or test results.

One last point to be considered is the place where the patient lives, and the places which are used for the registration and the study. If the patient needs to be moved from one hospital room to another due to the research, it is necessary to establish an environment with appropriate equipment and personnel to carry out the compulsory medical care. It is suggested that the provision of such conveniences is helpful in meeting the patient's needs and wishes (for instance, toilet/ bath in the study-room, tools and equipment for the comfort of the patient, adequate space and time to provide the usual interaction between the patient and the family members, etc.). Hence, the study can be conducted without doing substantial injustice to the patient's routine medical treatment and care.

In clinical trials carried out on sick children, blood and urine samples must be frequently and repeatedly taken and this causes distress and discomfort in children and parents. For example, the majority of pharmacokinetic studies are carried out through blood samples taken with repeated venous punctures. Excessive decrease in blood volume (the amount of blood taken in the sample exceeds $10 \%$ of the total circulating blood), pain, ecchymosis, infection, and the possibility of developing anterior interosseous syndrome are among the leading risks associated with repeated venous sampling. Pain, ecchymosis, infections, bone damage, anxiety increase, and the occurrence of potential errors in drug measurement are also stated in repeated blood sampling from the fingers or heels of infants. Studies have shown that the use of silicone venous cannulas or heparinized small-scale injectors significant- ly reduces the risks and complaints listed above, and central venous catheters can be used in case of medical indications.

It has been stated that obvious developmental changes in renal function influence the pharmacokinetics of drugs and that repeated urine sampling are important in indicating the renal clearance of the compounds excreted from the kidneys and the hepatic transformation pathways affected by the disease process. Therefore, it is suggested that the appropriate collection of urine samples can improve the quality of the pharmacokinetic study and contribute to the elimination or prevention of problems accompanying the procedure. As long as there is no indication for bladder catheter placement, the use of urine specimens which are self-drained is recommended. In young children and infants who have not received toilet training, new approaches are being tested since externally applied urine collection devices leak, and it is impossible to obtain urine samples which are not contaminated with faecal material from the baby's diaper. It is stated that an external collection device would be placed and appropriate urine would be collected through urine aspiration after each discharge for male infants. In children, who have received toilet training, it has been shown that an appropriate sample can be obtained under the supervision of a research nurse or through the motivating influence of the parents who understand the importance of obtaining a sample. In the collection of repeated blood and urine samples, it is possible to provide the least harm for the children participants and to increase the scientific value of the research when the above-mentioned risks are evaluated by the researcher (1).

\section{Controversial Historical Process Related to Paediatric Studies}

In the USA, the National Commission established on the Protection of Volunteers in Biomedical and Behavioural Research published a research report on children in 1977. Jonsen, a member of the commission, noted the difficulty of determining the requirements for the children and their legal representatives regarding receiving the informed consent of the volunteers for the participation in biomedical and behavioural research (2). When losses caused by less stringent standards are confronted for therapeutic research, another exception for individual consent is not as problematic, more explicitly, authorizing the parent or guardian to determine whether the child would participate in the trial if the research does not exceed the minimal risk of harm for the volunteer. The difficulties arising with this exception are concentrated around the uncertainty of the term "minimal risk". This exception still has challenging effects and the solution is yet far. Participation of children in research, who do not have any direct benefit for themselves, is strictly prohibited. This prohibition was considered as a barrier to performing medical examina- 
tions and similar procedures to collect data on normal functions and using the standard psychological tests or observational tools. From the theoretical point of view, it has been advocated that, legal representatives must give their consent by proxy or should educate the child so that he/she should make a sacrifice for one's interest to provide a consent at his/ her own discretion (assuming that the children will perceive this as an obligation to service the society, just as reasonable individuals having the ability to make decisions) (3). The idea involving the choice of parents' who think that the risk which children experience in their daily lives also includes the involvement of children in research with minimal risk is even more important. In this case, the same idea can be applied to other potential research participants who do not have the ability to make decisions for themselves, including adults who have several illnesses and disorders.

It is also remarkable that the first principle of the Nuremberg Code, which is "The voluntary consent of the human subject is absolutely essential", excludes children and those who have mental disabilities from research. This was cancelled by the Declaration of Helsinki and the concept of "legal supervision" was accepted. The USA National Commission had to deal with two things which were behind the principles mentioned in the Nuremberg regulation and Helsinki Declaration: Has a child's consent ever been asked or protected? Under what conditions would the consent of the legal representative be valid? What would be the ethical method to be used in a research that the society believed to be dangerous for the health of the child and that would use a child in such a situation? Were the legal supervisors who had to protect the benefits of the individual they represented conscious about the research?

In the US, when the National Commission was addressing the Children's Report, they were faced with a strong obstacle: The theologian Paul Ramsey strongly opposed to any research that did not have direct benefit for the children (4). However, the Commission accepted the view that "if a reasonable assumption can be provided with regard to the child's consent, non-therapeutic research may be allowed". The members had to make decisions on some issues such as the "conscious individual", the level of risk that a "conscious child" can accept, the expected or predicted benefit for a child, and benefits of the research results to be provided for other children and society. This would be the only way to make "reasonable assumptions". Therefore, terms such as "minimal risk", "little deviation from minimal", "higher than minimal risk", "plausible experiences" and "important benefit" have been introduced into the recommendations of the Children's Report. The Commission realized that these concepts should be defined. Questions such as "Minimal risk to what point?", "Minimal risk from whose point of view and under what conditions?" started to be asked. The exception regarding studies that do not exceed minimal risk revealed the principle that it is acceptable to expose people, who did not give consent, to some risks for the benefit of other larger groups rather than for their own benefit. But if "minimal risk" is acceptable, what would be the issue of allowing participation when there is "a little more than minimal risk"?

As can be seen, risk assessment is the most important step in the evaluation of the protocol and in the conduct of the research. Risks can be biopsychosocial, as well as occurring immediately or with delay, they may change according to age groups. Paediatric studies should be analyzed in terms of possible risks, including risks that may not normally be taken into consideration in adults because medication or methods may cause adverse effects in children who can not be defined as adults. The researcher is responsible to carry out an integral analysis of the risks in the study and to define the situation in the protocol so that the Ethics Committee can issue an approval decision. Identification of the risk levels and the possible benefits serve as the basis for ethical approvals. Risk should be monitored continuously, and there should be stopping criteria in the protocol for scheduled and unscheduled analyses in conjunction with safety and violation of the rules.

The fifth and sixth recommendations of the Children's Report of the USA National Commission were also open to argument. The fifth recommendation stated that "research in which more than minimal risk to children is presented by an intervention that does not hold out the prospect of direct benefit for the child may not be carried out", and five conditions were determined for the approval of such research. In the sixth recommendation, it was stated that based on the five conditions mentioned in the fifth recommendation, an unapproved study could be approved by the National Ethical Advisory Board if "the research presents an possibility to understand, prevent or alleviate a serious problem affecting the health or well-fare of children". These two recommendations destroyed the integrity of the Commission. In the past, almost all decisions had been unanimous. As a result, this Commission, which gave priority to the principle of autonomy and the rule of conscious, voluntary, informed consent, has paved the way for accepting that a volunteer whose consent was not obtained could be used in research that has no direct benefits for him or her, or more precisely, that legal representatives may protect his/her best interests on behalf of him/her.

In the Children's Report of the National Commission, the principle of "not harming" is very common although it is not clearly written. Since children cannot give consent in general, the principle of "not harming" outweighs the principle of ensuring autonomy. However, the principle of "not harming" must be refined in the content of the research. It is necessary 
to explain the reasons of the damage, and how the research can damage the children. Many research actions are not harmful, but they have the risk of harm. As observed in Nazi researches, damage such as deliberate death or causing permanent disability are definitely not ethical. How should be the damage from a blood collection needle be evaluated? If a child is healthier than a child with leukaemia who is routinely exposed to this needle, would the needle be considered as more risky and harmful? Is making changes in daily activities for research observations harmful or is there a risk of harm? Would this change be harmful or has the risk of harm if it involves leaving the child in custody of a person who is unknown, instead of leaving him/her with the familiar babysitter? Would being randomly selected for a treatment plan which is later understood to be the least effective of the treatments tested be considered as harmful? Such views on damage and risk are important to make reasonable judgments about applying the principle of "not harming" or ignoring it. This provides a general framework for making such a judgment.

As can be seen, the principles which are applied when encountering any ethical problem, are measured according to the circumstances. Any principle that is sufficiently correct in itself can become important and appropriate (or unimportant and inappropriate) within such a real situation. Principles are evaluated on a background set by specific circumstances. If the background is changed by adding or removing or highlighting or hiding certain conditions, then this or that principle would become more central and visible. Understanding them is an important part of moral judgment.

\section{Grouping of Children According to Age}

Today, the period from the birth to the end of adolescence is called "childhood", and therefore, the term "research involving children" means research on the individuals who were in this age group. Between 0-18 years, there are numerous widely accepted physical, cognitive and psychological characteristics, which are widely accepted as indicators of the normal childhood developmental process, such as independently being able to walk, talk, socialize, create abstract concepts, and being able to make independent choices. There are also many differences among children who are thought to have one or more of these characteristics commonly. Studies carried out on this subject suggest that there are mainly three age groups within the child population, and some children "on the margins" of these groups can be considered in the nearest category.

1. Birth-7 age group: Children at early ages, who are most in need of protection from harm and at the same time should be constantly looked after and raised. It is not possible to obtain a consent of a child in this age group. He or she should not be expected to understand the research.
2. 7-14 age group: Children at the middle of maturation are children who can protect themselves from harm to a degree, but are in need of care as they are not adults yet. Children can understand the risk/benefit assessment of a study as from nine years old, however, they have difficulties in understanding conflicting interests or non-tangible information. This situation should be taken into consideration in preparing information forms for children. Most of the children, even some parents, may not understand randomized grouping. In addition to this, it can be said that particularly children with chronic illnesses are more capable of having independent decisions depending on their experiences. In every situation, informing the child, preferably having his/her consent in writing if he/she at the school age (6-7 years of age), and being able to monitor this consent are important issues.

3. 14-18 age group: Older children have the ability to protect themselves from harm, and these children need to be trained to reach adulthood (5). Research on adolescents is always difficult. They are still involved in the paediatric age group although they have the ability to make decisions as adults in many other areas of life. When the consent of an adolescence is being requested, there must be a balance between their independent decision-making ability and the need to be protected by the parent/ guardian. It has been shown in many publications that adolescents can make independent decisions under certain circumstances.

This classification seems compatible with the categorization based on Piaget's cognitive developmental stages and includes the stages of infancy (0-2 years), first childhood (2-6 years), middle childhood (6-12 years) and adolescence (1218 years). The notable difference between these two classifications is that infancy and first childhood are classified as a single group in the first classification. However, this is only apparent superficial difference. It is an acceptable approach for children from birth to 7-8 years old to be in the same group when considering their need for care and participation in decision-making processes.

It is known that each child has his or her own characteristics regarding the developmental stages of children. The transitions between periods including the transition from childhood to adulthood and taking into consideration the individual differences are important for the protection and the training of the child, the development of autonomy, supporting the potential of the individual, and determining the most basic needs of the child (health, education, food, etc.). Contrary to the opinion of adults, children are closely interested in issues such as illness, health, disability, pain, distress, and agony that affect their own development, and they search for 
their "goods" in these issues. It should be accepted that children try to protect their benefits in terms of right to choose, privacy, truthfulness, reliability, and self-awareness just like adults but different levels of understanding.

The issue that a child can give a consent or not should be based not only on his/her calendar age but on other factors as well such as his/her developmental stage, mental abilities (particularly in children who have special needs and/or have a learning disability) and life/disease experience. If the child's consent cannot be obtained, this should be documented with its reason in the consent form bearing the signatures of the parent/legal representative and the researcher. The child's decision alone is not sufficient to participate in the research unless it is supported by the informed consent of the legal representative.

Ethical and Legal Responsibility for Clinical Researches on Children

The international text on human rights and the protection of human dignity regarding the application of biology and medicine is the Convention on Human Rights and Biomedicine signed in Oviedo (Spain) on April 4, 1997 (Convention for the Protection of Human Rights and Dignity of the Human Being with Regard to the Application of Biology and Medicine: Convention on Human Rights and Biomedicine; Oviedo, 1997) (6).

The Member States of the Council of Europe and other states (and the European Community), which have signed this Convention, have decided that measures should be taken to secure human dignity and to protect the fundamental rights of the individual in terms of the application of biology and medicine on account of the fact that the misuse of biology and medicine would cause actions that would put human dignity in jeopardy, and accepted the issues expressed in the agreement.

Article 16 of the Convention concerns "the protection of persons undergoing research". Research on persons who are able to consent to research: Research on persons, who are able to consent to research, may only be conducted if all the following conditions are met (Article 16) (6):

i. There should be no other alternative of comparable effectiveness of the research on humans;

ii. The risks which may be taken by that person should not be disproportionate to the potential benefits of the research;

iii. The research project must be approved by the competent body after an independent examination of its scientific merit and a multidisciplinary review of its ethical acceptability; iv. The persons participating in the research must be informed of their rights and the safeguards prescribed by law for their protection;

v. A free, open and private consent of the volunteer must be obtained and documented. Such consent may be freely withdrawn at any time.

Research on persons who are not able to consent to research: The Convention sets additional measurements for the protection of persons who are not able to consent to research (Article 17). Research on a person without the capacity to consent, may be conducted only if all the following conditions are met in addition to the above-mentioned conditions (Article 16).

i. The results of the research must have the potential to produce real and direct benefit to the volunteer's health;

ii. It must not be possible to conduct a research of comparable effectiveness on individuals capable of giving consent. In other words, if comparable results can be obtained from the studies carried out on individuals capable of giving consent, those, who are not capable of giving consent, cannot participate in the research as a volunteer.

iii. The necessary authorization must have been issued specifically and in writing by the legal representative or an authority, person or institution specified by law;

iv. The person concerned should not object to participating in the research (6).

The Helsinki Declaration of the World Medical Association concerns recommendations that guide doctors in biomedical researches involving volunteers. The seventh and last revision of the Declaration of Helsinki, which is regarded as the cornerstone of the ethics of clinical research, has been accepted in the 59th General Assembly in Forteleza in 2013. As various minorities, women and children are not sufficiently involved in research projects and as these groups cannot make use of research results sufficiently, the issue of providing adequate access to these groups was re-emphasized after the revised declaration in 2008, and made even more clear in the 2013 revision (7).

Articles 28 and 29 of the Helsinki Declaration are related to receiving informed consent, and specifies the conditions for carrying out a research on those who have no capability to give consent (7).

28. For a potential research subject who is incapable of giving informed consent, the physician must seek informed consent from the legally authorized representative. These individuals 
must not be included in a research study that has no likelihood of benefit for them unless it is intended to promote the health of the group represented by the potential subject, the research cannot instead be performed with persons capable of providing informed consent, and the research entails only minimal risk and minimal burden.

29. When a potential research subject who is deemed incapable of giving informed consent is able to give assent to decisions about participation in research, the physician must seek that assent in addition to the consent of the legally authorized representative. The potential subject's dissent should be respected.

Regulation on Clinical Trials (2013) Article 6 is related to the participation of children in research and is as follows (8):

In the cases when the research subject is directly related to children or is a clinical situation that can be examined only on children or it is mandatory for the data obtained as a result of the research made on adults to be confirmed to be valid also on children if the research does not have a predictable risk in terms of volunteers' health and there is a general medical opinion suggesting that the research would provide a direct benefit to the volunteers, it may be allowed to conduct research on children within the framework of the points specified in Article 5 and the points specified below.

a. There should be a general medical opinion suggesting that there is no known risk of the product or practice to be researched on children.

b. If the child is able to express his consent, and if he is not able to do so his parents' consent or the consent of guardians, if he is under guardianship, is obtained in writing after they are all informed.

c. The child is excluded from the research in the cases when he rejects to participate in the research or wishes to leave the research at any stage of the research.

If the child is able to make an assessment and reach a conclusion about the information provided to him, all the information regarding the research is told to the child accordingly.

d. Ethical committee is informed by a physician, who specialized in children's health and diseases, about the clinical, ethical, psychological and social problems regarding the research whereas it is informed by a dentist, who did a doctorate of residency in dentistry, about research regarding dentistry and the protocol is assessed accordingly.

e. The ethical committee cannot approve this trial without the affirmative opinions of a physician, who is specialized in children's health and diseases, in clinical trials to be conducted on children, and a dentist, who did a doctorate of residency in dentistry, about the research regarding dentistry, with regard to that the research can be carried out on children. f. Any convincing or financial offer other than covering the mandatory cost that would result from children's participation in the research cannot be made in relation to the clinical researches to be made on children (8).

\section{Conclusion}

In conclusion, special conditions are required for the research to be carried out on children. The reason for this is that the children have no capacity and authority to make decisions about their own bodies, and they are not able to defend their rights and interests by themselves.

To conduct a study on children,

- It should be envisaged that the research will make a significant contribution to science.

- Research should have the quality to be performed only in children.

- Risk/benefit balance must be acceptable.

- Written information must be given.

- Informed consent must be received.

- Sufficient time must be given for the consent.

- The child should be able to withdraw from the study without any reason whenever he or she wants, and the treatment process should not be affected, or the child damaged due to this reason.

- Consent must be obtained by the research coordinator.

The application of a new treatment on children or the ethics of the research to be carried out on them are being discussed in various contexts in various aspects. Researchers should know that the research is a partnership with family, guardians and children. It is not a process performed on children. The personal risk of the research on the child carries not only the risk of the process, but also the social, emotional and medical risks that the child has been exposed to or would be exposed to in the future. The researchers should also consider whether the research process will cause any mood disorder or behavioural disorder on the child. The scientific findings of the research and the emotional and behavioural outcomes of the study on the individuals involved in other research should also be carefully examined.

Peer-review: Externally peer-reviewed.

Conflict of Interest: The author has not reported a conflict of interest. Financial Disclosure: There is no financial support in this study. 


\section{References}

1. Kauffman RE, Kearns GL. Pharmacokinetic studies in paediatric patients. Clinical and ethical considerations. Clin Pharmacokinet 1992;23:10-29. [CrossRef]

2. Jonsen AR. The weight and weighting of ethical principles. The ethics of research involving human subject. Harold Y (ed). Maryland: Vanderpool Univ Publ Group, 1996:59-83.

3. Mc Cormick RA. Proxy consent in the experimental situation. Perspect Bio Med 1974;18:2-20.

4. RAMSEY P. The enforcement of morals: nontherapeutic research in children. Hasting Center Report 1978;8:7-9.
5. Miller J. National Council on Bioethics in Human Research, Ottowa, Canada, personal communication, March 1993 in Biomedical Issues in US Public Policy. (http://www.nus.edu.sg/irb/Articles/Biomedical\%20 Ethics\%20in\%20U.S.\%20Public\%20Policy.pdf). [CrossRef]

6. https://rm.coe.int/168007cf98 [CrossRef]

7. http://cdn.istanbul.edu.tr/FileHandler2.ashx?f=helsinki-bildirgesi-2013[1]. $p d f$ [CrossRef]

8. http://www.titck.gov.tr/PortalAdmin/Uploads/UnitPageAttachment/ e5a1e31511882.pdf [CrossRef] 